\title{
The Rise of Big Data and Land Engineering Disciplines
}

\author{
Lu Zhang* and Zenghui Ma \\ Shaanxi Land Construction Group, Xi’an, Shaanxi 710075, China \\ Key Laboratory of Degraded and Unused Land Consolidation Engineering the Ministry of Land and Resources of China, Xi'an, \\ Shaanxi 710075, China \\ ${ }^{*}$ Corresponding author
}

\begin{abstract}
With the development of the times, "big data" has begun to enter people's lives, and it has also increasingly changed the way people think. As an emerging discipline, the development of land engineering disciplines is inseparable from the support of big data.
\end{abstract}

Keywords—big data; land engineering; subject construction

\section{INTRODUCTION}

The big data wave whistled.

In the Internet age, "big data" has become an important resource for human society that is growing in a geometrical manner, and it affects the development and transformation of today's human society. The "big data" boom in the internet age has rapidly spread to all areas of the economy and society. The land engineering discipline is a natural testing ground for big data research and application. Focusing on the rise and collision of land engineering disciplines and big data, the transformation of the way of thinking and methodology brought by big data, the integration of research objects and contents of land engineering, and the innovation of planning and design technology. The opportunities and challenges brought by big data to land engineering research and development.

\section{NEW DISCIPLINE LAND ENGINEERING}

\section{A. Changes in Thinking Patterns Spawned Land Engineering Disciplines}

Firstly, the way of thinking and methodological changes. The Eastern and Western thinking modes and methods vary in solving complex problems. Big data attaches importance to "relevant" relations and weakens the study of "cause and effect" relations, which pays more attention to the perception of people and social space, and provides new ideas and methods for the study of the complexity of land engineering disciplines and breaks through the western reduction theory and develops the whole. On system theory. Land engineering is an emerging cross-disciplinary subject that involves natural, social, economic, engineering, and many other factors, which is an open and complex system. The traditional research methods, surveying experiments, project planning and design of land engineering mainly depend on theoretical modeling driven from the top down, and pay more attention to physical space perception, which often through random sampling, and then trying to use the model to restore the entire picture, the main research effort is focused on data acquisition, sampling and reduction methods, but often exclusive data is the core resource of academic research. The empirical research under observation driven by big data highlights the emergence of "bottom-up" full-sample big data, liberating scholars from collecting data and processing data, and focusing on improving the ability to solve problems with data. Resolving land engineering disciplines due to too many involved factors, which is difficult to model and cannot highlight the integrity of the comprehensive land consolidation of "fields, waters, roads, forests, and villages", and truly play the value of big data. The research and application of big data has changed the traditional way of thinking and methodology.

\section{B. The Research of Land Engineering is Inseparable from Big Data}

Secondly, the integration of land engineering research objects and content. The research object and content of the land engineering discipline are using engineering methods to solve land problems, turn unused land into usable land or make efficient use of land that has been used, and actively coordinate the harmonious development process of people and land ${ }^{[1]}$. Big data has the characteristics of large capacity, diversity, rapidity, and low value density, referred to as $4 \mathrm{~V}^{[2,3]}$, which is in line with the research object and process of the "collegiate coordinator and land relationship" of the land engineering discipline. Big Data provides a large amount of data on "people", making it possible for people-to-people relationship research to focus more on "people" and better reflect peoplecenteredness. From the macro-meso-micro level, we can dynamically reveal the pattern of human spatial activities and spatial behavior, and shift the study of land engineering from static space to dynamic space. Macro level, social network big data, search big data, mobile communication big data, acquisition and application of space remote sensing big data, which can dynamically reveal the dynamic development of urbanization and rural hollowing out of land for construction use in land engineering disciplines, and provide scientific basis for urban and rural planning and development research and comprehensive land engineering renovation. Meso level, positioning and navigation big data, transportation intelligence big data analysis and application, which can reveal the spacetime and behavioral trajectories of urban and rural personnel 
and reflect the potential of agricultural land, construction land development and rearrangement, and later-stage utilization methods, provide scientific basis for planning and design. Micro level, refined analysis and application of big data on agricultural machinery operations, big data on production and energy consumption, and data on agricultural production of the Internet of Things (crop growth, crop yield, soil stability, and dynamic changes in soil physical and chemical indicators), which can reveal the mechanism and dynamic changes of water, soil, gas, and life, and provide data and decision support for the sustainable use of new cultivated land and new construction land.

\section{Big Data Drives Discipline Method Innovation}

Finally, planning and design innovations in technology methods. Driven by big data, the research content has been transformed from static space to dynamic space. The corresponding planning and design techniques should also be changed from static planning to dynamic planning. One of the theoretical foundations of traditional land remediation planning is the statistical and linear prediction model. For complex land engineering systems with increasing uncertainty, the planning and design of new technological methods deal with nonlinear, self-organizing, and high-dimensional complexity issues. The planning content should shift from a single special plan to a comprehensive overall plan. The traditional planning tool GIS focuses on the expression and analysis of the "earth", and is a GIS oriented to the "earth". It does not express enough the "people" in the regional human-personal system, that is, individuals, groups, and organizations. So a "human-computer interaction" dynamic programming platform based on big data should be established to effectively organize and apply data, information, and knowledge in the field of land engineering. Future planning and design work should adopt a dynamic planning platform to highlight people's dominant decisionmaking and planning and design status, which should not affect the planning and design process and results due to insufficient data acquisition and processing lags. We should make full use of data mining techniques, computational experiments, and other big data technologies to prevent data from appearing only in a fragmented manner in the process of planning, lack of horizontal coordination, and lack of vertical flow. We should jump out of the traditional planning, especially statutory planning, and extend and expand the content, effectiveness, and execution of the plan.

\section{CONCLUSION}

In short, what big data brings to the discipline of land engineering is not only the innovation of research content and technology, but also the transformation of thinking methods and ideas, which is a revolution, an opportunity, an important milestone for the soaring of land engineering disciplines.

\section{ACKNOWLEDGMENT}

This work was financially supported by Shaanxi Province Land Engineering Construction Group Research Project "Moisture Characteristics and Transport Law of Mixed Media in feldspathic sandstone and aeolian sandy soil in Mu Us Sandy Land (DJNY2017-23)" fund.

\section{REFERENCES}

[1] J. C. Han. Introduction of land engineering. Beijing: Science Press, pp. 5-12, January 2013

[2] X. L. Li, H. G. Gong. A survey on big data systems. Chinese Science: Information Science, vol. 45, num.1, pp. 1-44, 2015

[3] Z. F. Wu, Y. W. Chai, A. R. Dang, et al. Geography interact with big data: Dialogue and reflection. Geographical Research, vol. 34, num.12, pp. 2207-2221, 2015. 